\title{
Measuring the Threat of Competition - Elderly Services in the City of Stockholm
}

\author{
Roland Almqvist ${ }^{1}$ \\ Institute of Local Government Economics \\ School of Business \\ Stockholm University \\ S-106 91 Stockholm, Sweden \\ E-mail: ra@fek.su.se \\ Published in Local Government Studies, vol. 25, no. 1, pp. 1-16, 1999 \\ Frank Cass, London
}

\begin{abstract}
This paper sets out a method for the purpose of isolating effects of the competition threat. The case investigated is care of the elderly in the city of Stockholm, which introduced competitive tendering for the 1993 budget year. Three approaches - based on three simple quantitative models - have been presented for the purpose. Cost-cutting with respect to fulltime annual staff appointments has been a consistent variable in all three models. However, this has been juxtaposed with a number of changing variables.

Initially, each unit's savings were compared with the saving requirements of the unit concerned. In a second model, the unit managers were divided into two groups: those who perceived a threat of competition during the period that the competition programme was applied, and those who did not. A third model was also applied in which the unit managers themselves had to estimate how large a proportion of the unit's savings they were willing to attribute to the fact that it faced competition.

The result showed that one plausible assumption is that the threat of competition has had an effect in the form of savings. This effect - regarded as a mean - may be estimated at a cost reduction among these units of between 4 and 6 per cent.
\end{abstract}

\footnotetext{
${ }^{1}$ I would like to thank Professor Ernst Jonsson and dr. Olle Hogberg, Institute of Local Government Economics, Stockholm University and also Professor Stephen Bailey, Department of Economics, Glasgow Caledonian University for helpful comments. Errors are my responsibility.
} 


\section{INTRODUCTION}

Over the years, a series of evaluations and comparisons of private and public management have been carried out. The findings usually indicate that activities pursued in competition are more cost-effective than those run in the absence of competition. The evaluations also suggest that it is competition - rather than who owns the enterprise - that promotes efficiency (Bishop \& Kay, 1988), i.e. that it is relatively unimportant whether the activity is conducted under private or public auspices. A private hospital is no more efficient than a public one simply because it is privately run. Instead, the argument is based on the proposition that a hospital that operates in competition with other hospitals is probably more efficient than one that does not. Accordingly, the focus should be on the situation with regard to competition, not the facts of ownership (Harrison et al, 1990).

Theories have also been developed that suggest that it is the threat of competition - not competition itself - that provides the spur (Baumol et al, 1988). These theories are, broadly speaking, based on the notion that an activity occupying an exclusive position must act efficiently in order for potential competitors not to become interested in attempting to enter the market. From the monopoly activity's point of view, then, efficient action and a normal return on capital investments help to keep potential competitors at bay. Dodgson \& Topham (1988) point out that competitive conditions arise not only because of the existence of classic perfect competition, but owing to the potential of possible competitors. In their view, too, the threat from possible competitors constitutes a guarantee that only normal profits are earned and that consumers are not exploited.

Sorensen (1993) further propounds a hypothesis that the absence of producer competition means that public administration is less efficient than it might be. Nevertheless, his opinion is 
that competition need not necessarily mean that several enterprises exist on the market. A market characterised by potential competition is one that every enterprise is able to enter, but a few or several perhaps choose nonetheless not to do so. The hypothesis also postulates that public-service activities can raise their efficiency if their monopoly position is threatened.

Altogether, the proponents of these theories may be said to argue that the possibility of competition in public administration coupled with the threat of external players possibly entering the market are the best way of guaranteeing efficiency in the services provided. This also guarantees that the players do not make excessive profits, that the consumers are not exploited and that quality remains high (Ellwood, 1996).

\section{Various forms of competitive threat}

Jonsson (1993) developed these theories of competition with reference to Swedish health and medical care. In his view, competition may take various forms:

- competition in a market in which various producers compete to sell their products to existing customers,

- competition between different producers for a market, i.e. for the right to be the sole producer for a certain period of time.

In the latter situation, competitive tendering may be conceivable. Thus, for example, various tenderers compete for the right to make use of the facilities and equipment of a unit (e.g. a block of service flats or a hospital) to conduct the activity during the contractual period. It is 
desirable for there to be several tenderers who are seriously interested in running the activity in question, but a single serious competitor to the producer in question may suffice to generate a competitive threat. A producer currently enjoying a monopoly position may thus be challenged to compete for the production right.

Following Jonsson's line of reasoning, it is reasonable to assume that not only competition as such, but also the threat of competition postulated by the theory can take various forms. If we consider the last form of competition mentioned above, the players who are in a monopoly position should initially find that the threat of competition is closely connected with whether they decide to introduce competitive tendering or not. If the decision to introduce it is taken, however, it is plausible to assume that the nature of the competition threat changes. It now becomes more immediate and probably comparable to that mentioned by Hambleton (1988), namely the threat of privatisation. In this situation, the monopoly position as producer should no longer be perceived as equally secure, since there is a risk of losing the contract to run the activity to an alternative, private producer. With both these degrees of competition threat, the effects may be expected to be those emphasised by Hambleton, namely that the threat of competition "shakes up" the public-service activity to some degree, bringing about a realisation that changes and improvements are required to prevent privatisation from taking place. This probably also means that the competition threat can be perceived in both negative and positive terms - either as a threat in the true sense of the word or as a challenge or opportunity.

The effects propounded in the theory may be considered plausible. One way of proceeding to acquire more knowledge of the phenomenon is to study it empirically. However, empirical contributions of this kind are conspicuously lacking, at least in public-service activities. Two 
preliminary questions that may be asked are how far the theory has practical relevance, and how the impact of the competition threat on the activity is manifested in such cases.

According to the theory, the activity facing competition should reduce organisational slack, becoming more efficient. If so, in practice this can certainly take place in various ways. One should be by means of cost-cutting in the activity (e.g. staff cuts); another is by raising its quality (e.g. concerning staff skills and availability/continuity in the form of staffing). It is also reasonable to assume that a threat of competition may, however, have both positive and negative repercussions. The positive ones have already been mentioned; the negative repercussions may, instead, be concern at the prospect of the new situation among staff affected by a threat of competition (Kerley \& Wynn, 1990). Moreover, it is conceivable that changes in attitude and behaviour among the staff have various repercussions, depending on

- how much support the new situation has received in the organisation,

- how the introduction of these new models of governance has been carried out.

The following study is intended mainly to make an empirical contribution to research on the effects of the threat of competition. The purpose is, by way of introduction, to investigate the degree to which the competition threat is perceived in a practical case, and if so to attempt to isolate and quantify its impact in the form of savings, if any. Other matters investigated are whether it is possible to discern any connections between the players' attitudes to the introduction of competitive tendering, and any cost effects.

The case investigated is the city of Stockholm, which introduced competitive tendering for the 1993 budget year. The study is also limited to an evaluation of the city of Stockholm's care of 
the elderly. The material is based partly on interviews with unit managers in this care sector, and partly on cost data collected by means of a questionnaire. Twenty-one profit centers randomly selected - were studied. Eleven of the units had already been subjected to competitive tendering in the first round of the "competition programme", while ten were still awaiting their turn when the study was commenced. The study was carried out in the years 1993-94.

\section{Background to the research project}

In its budget resolution for the year 1992, the Stockholm City Council stipulated a previously untested focus for the work of the city's boards and departments. This resolution had been preceded by a debate on the straitened financial situation of the city of Stockholm. In the politicians' view, the cost pressure on the city's finances must be reduced, and one means of achieving this was to be by subjecting activities to competition (Finance Department, 1992 and 1993). Accordingly, the budget directives for 1992 stated that:

\footnotetext{
The public monopolies are to be abolished as far as possible. There must be competition between the activities conducted by the city and those under private auspices... It is the public who should decide where they wish a particular service to be performed.
}

The view from the central management was that enhanced efficiency in the local authorities' areas of responsibility was, in the long run, the only alternative to a drastic reduction in service volume. The best way of ensuring a continued high service level for the citizens notwithstanding persistent savings requirements - was thought to be introducing competition. The hope was that, within the framework of this boost to efficiency, the city's costs could be reduced by 10 per cent and a substantial quality improvement simultaneously achieved. 
For the new budget year, 1993, the 17 district departments in the city of Stockholm were made responsible for exposing their activities in the social services to competition through competitive tendering. In some cases, the choice was made to introduce a purchase/provider model, with the purchasing units in charge of issuing the invitations to tender and examining the tenders submitted. The directives were that all services - except cash-financed activities and some official duties - were to be subjected to competitive tendering within a five-year period (i.e. 20 per cent of services each year).

The Stockholm "competition programme" thus included social services, such as care of the elderly and of drug abusers. In contrast, interest in previous competitive-tendering pilot projects in, for example, the United Kingdom has been largely focused on the "hard" services, such as street and park maintenance, refuse collection, catering, etc (Bailey \& Davidson 1997, Kerley \& Wynn, 1990, Knox \& Young, 1995, The local Government Management Board, 1995, Walsh 1989 and 1995). Moreover, in Stockholm - unlike the UK - competitive tendering for the provision of social services was to be compulsory, which gave the central management guarantees that competition really would be introduced.

The successive introduction of competitive tendering opted for by the city of Stockholm in drawing up its competition programme may be expected to entail an additional aspect of the competition threat besides those dealt with in the foregoing section. This aspect is the threat that the players may perceive owing to uncertainty about whether their activity is in line for competitive tendering in the next stage or not. The players in question do not know, after all, whether their activities will come in for competitive tendering or not when the next fifth of 
services to be subjected to competition are chosen. Consequently, this aspect of the threat of competition has also been relevant for this study.

The cost impact - such as the quality issue - of competitive tendering effected in the city of Stockholm has been studied within the framework of this research project (Högberg, 1996, Jonsson, 1996). The results show that competitive tendering for care of the elderly was responsible for savings of some 10 per cent without any changes for the worse concerning the quality. But according to the theory the units that had not yet been subjected to competitive tendering should also have taken steps to become competitive. Thus, an attempt to assess the impact of the competition threat is necessary since this, too, may have brought about considerable savings. This part of the project is presented in the present study, but it focuses the cost impact, rather than the quality issue. I will also make clear that the paper sets out a method for quantifying the savings within the local government sector rather than providing representative results for local government as a whole.

The cost data studied related to changes in the number of employees, expressed in terms of full-time annual staff appointments. This was prompted by the fact that they make up such a relatively high proportion (75 per cent) of the units' total costs (Statistics Sweden, 1992). Accordingly, they might be expected to be particularly interesting to unit managers with profit responsibility when the time comes for them to "put their own affairs in order".

\section{COST EFFECTS AMONG PROFIT CENTERS}

The data collected show that personnel strength had been reduced in 18 of the 21 units since the introduction of the competition programme. Two of the units had an intact workforce, while one unit had enlarged it. For the units that were subjected to competition in the first 
round, this applies to the period until the onset of competitive tendering, while for the other units the entire period studied is, instead, relevant. In other words, the units concerned undertook these measures during the period when a threat of competition, if any, existed. The contributions of the measures to the savings effected may be expressed in percentages of the workforce, as in Figure 1 below.

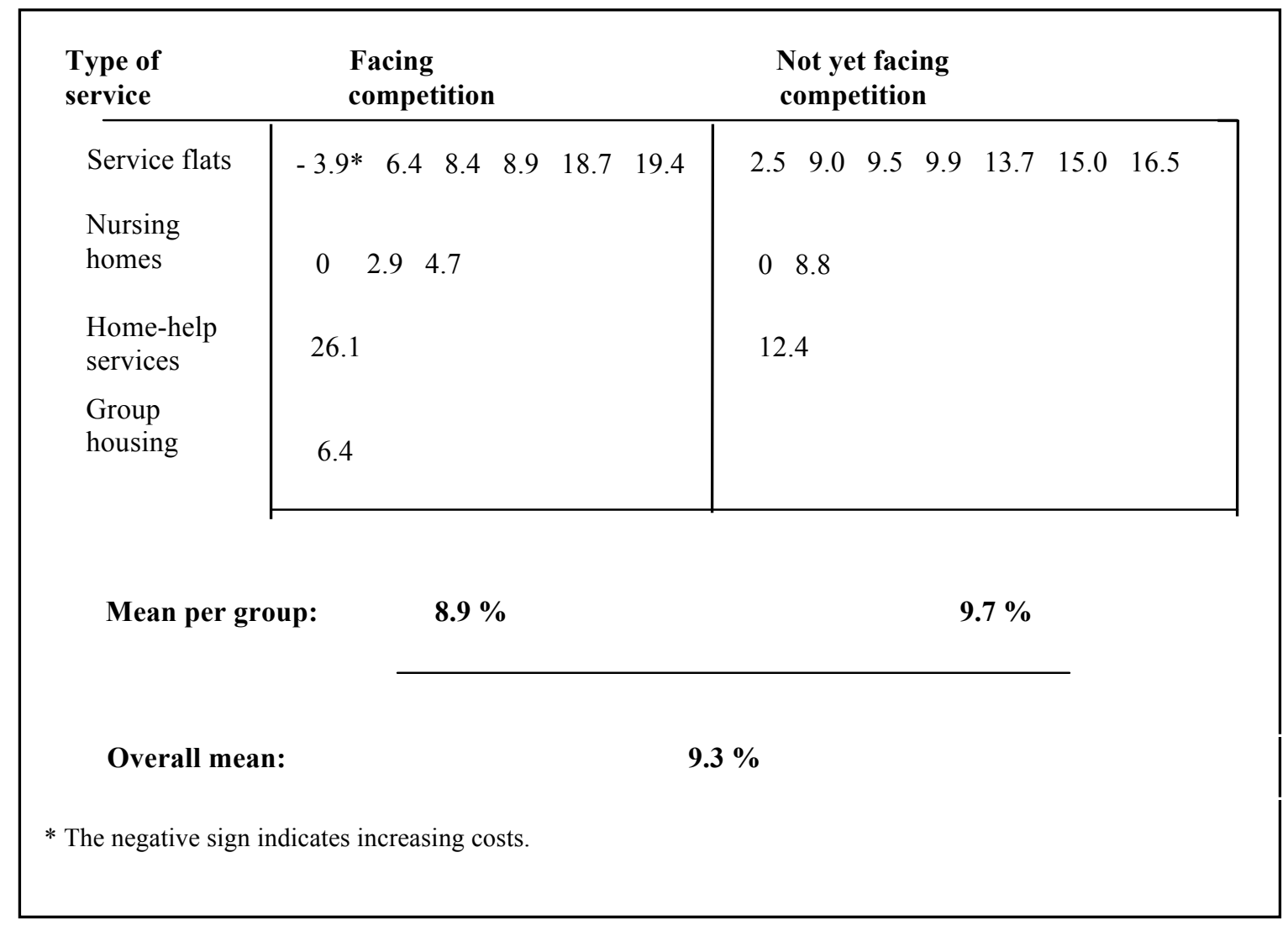

Figure 1. Units' savings as percentages of full-time annual staff appointments.

Clearly, the first two years that the competition programme was in effect were characterised by savings among the units studied. In round figures, costs were cut by some 9 per cent in terms of full-time annual staff appointments. It is worth noting that the units that had not yet been subjected to competitive tendering also implemented relatively large savings. The units 
subjected to competitive tendering might have been expected to achieve considerably larger savings than the others.

However, one explanation why this is not so may be that the units under local-authority management were considered sufficiently competitive for the first round of the tendering procedure, and those involved possibly held the view that further efficiency-boosting measures were unnecessary. Indeed, the comments during the interviews also expressed the view of most unit managers that the local-authority tenders were competitive. Another possibility is that external care providers' competitive capacity was underestimated. Specific comparisons with other care alternatives had not been carried out previously, and it is plausible to assume that knowledge of the costs and quality of local-authority management in relation to external care providers was inadequate.

What, then, brought about these savings? The straitened financial situation of the previous few years meant, after all, that savings requirements had been imposed on most social-service districts for the forthcoming budget year. Consequently, it is possible that the savings are explained by the current savings requirements. Initially, it is therefore appropriate to check the savings requirements imposed on the social-service districts and juxtapose these with the savings actually achieved. Figure 2 shows savings alongside the savings requirements in 19 of the units studied. The light bars represent the actual savings of the units in question, while the dark ones show the savings requirements imposed on the units during the period. 


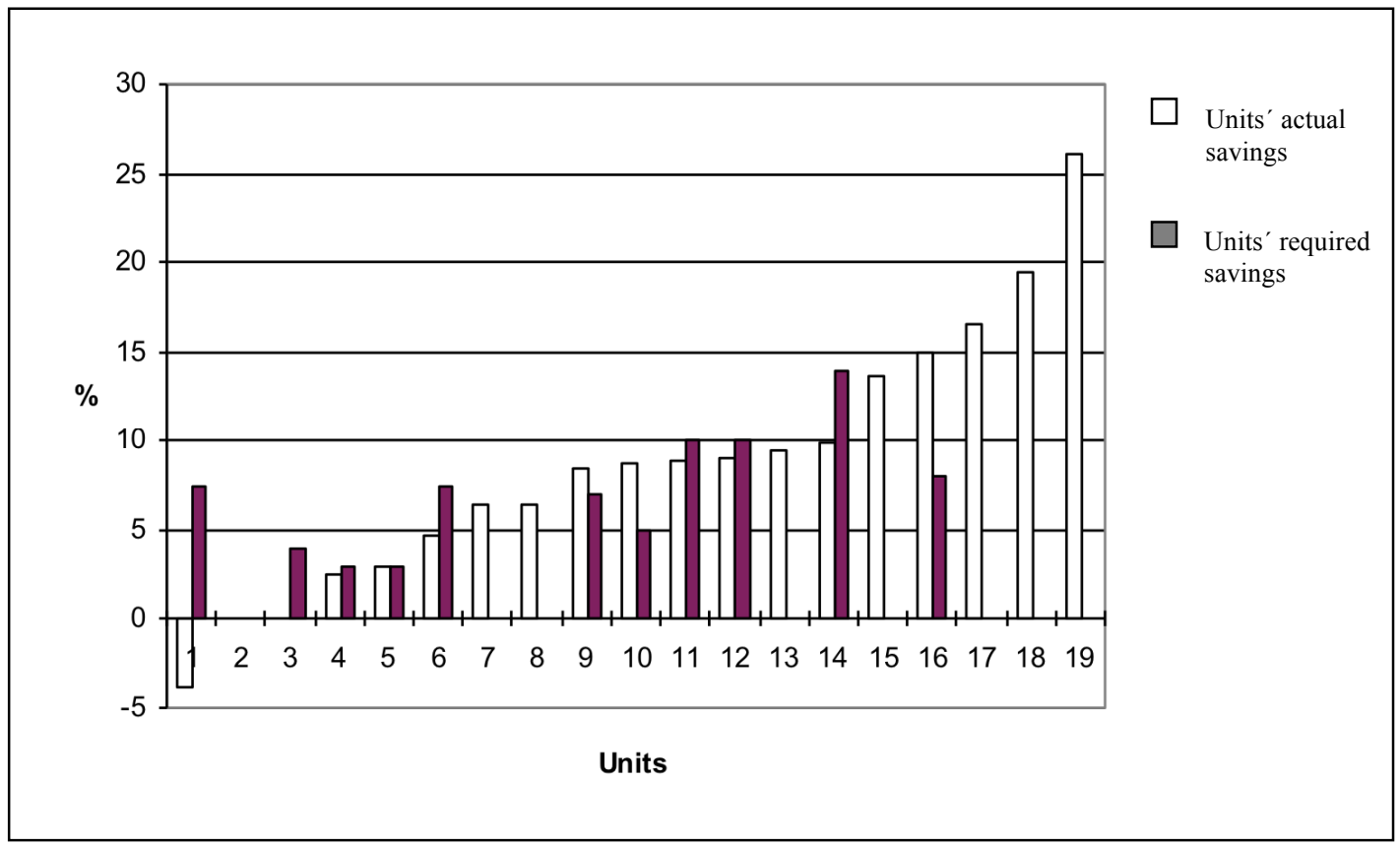

Figure 2. Units' savings in relation to savings requirements.

Seven units failed to fulfil the savings requirements imposed on them, and one unit barely did so. But there were also three units that exceeded the requirements to a varying degree, and also seven units that effected savings without any requirements being imposed at all. A plausible assumption is therefore that the savings requirements do not fully explain the savings in every case, and there are reasons to suspect that the competition programme had some impact.

One way of attempting to isolate the impact of the threat of competition is to divide the respondents into two groups: those who perceived and those who did not perceive any competition threat while the competition programme was in force. The argument would be that the difference, if any, in savings between these two groups may be an effect of the threat of competition. The results of the comparison are shown in Figure 3. 


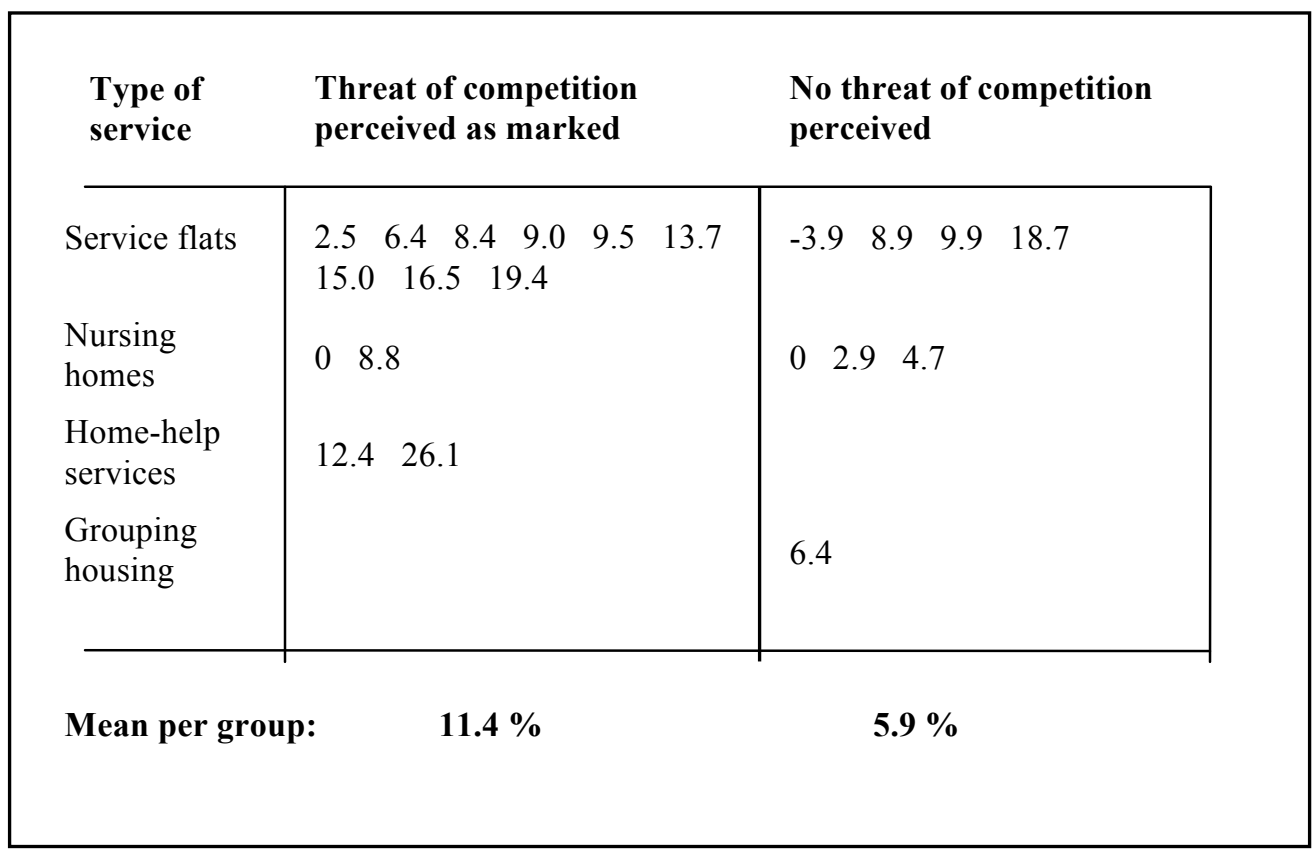

Figure 3. Savings related to the threat of competition perceived and not perceived.

The difference between the two groups is between five and six percentage points, and one possible interpretation is that this difference is an effect of the threat of competition. But for a more detailed clarification of the problem it is appropriate also to base the analysis on the unit managers' explanations for the cost-cutting measures in their activities, and their own estimates of the impact of the competition threat.

During the interviews, frequent explanations given were that the measures were carried out for the purpose of fulfilling the budget, enhancing quality and making the activity more efficient. But one essential difference between the two above-mentioned groups was that the managers who perceived a threat of competition more often mentioned a wish that their accounting unit should become more competitive as one purpose of the measures. Remaining as a care provider or being allowed to "take over" the activity were additional factors mentioned. Those who perceived a competition threat also admitted more frequently that their interest in taking measures to improve efficiency and cut costs were influenced by the fact that care of the elderly in the city of Stockholm had become subject to competitive tendering. 
On the basis of the unit managers' descriptions, the image of a competition threat thus begins to emerge. The question that now comes to the fore is whether it is valid to interpret the difference in cost-cutting between the two above groups as an effect of the threat of competition. A third approach here may be helpful: that of asking the unit managers themselves to appraise the impact of the threat. In the interviews, all the unit managers were therefore asked how large a proportion of the change in costs in the unit they thought was attributable to the fact that the city of Stockholm had introduced competitive tendering.

The managers' assessments varied widely. Some considered that the savings in the unit were in no way caused by the fact that it faced competition, while others thought the savings were entirely due to this fact. Some also considered that the unit's savings could not be attributed directly to the existence of competition, but that the reform nonetheless hastened their implementation. It is therefore reasonable to assume that the threat of competition had a varying degree of influence. The interviewees' comments cited below also give a picture of the range of answers to the question of how large a share of the savings was attributable to competition:

'I don't think this is connected with becoming subject to competition, in fact. We've deliberately reduced our costs anyway. That is, we've become more financially aware in general. After all, no one's told us to stick to the budget, so we'll be in a good position if we face competition. But obviously, if I were obliged to submit a tender it would of course look better if I'd run the activity with a surplus as the result instead of a deficit.'

'The whole lot, probably. If this had been in the 1970 s or early ' 80 s I'd never have taken these measures. I've now made staff cuts at certain times, and I would never have done that before. The 
fact is that one thinks in terms of savings nowadays. You can't show off the city of Stockholm's highest daily care rate.'

\begin{abstract}
'You review the work. After all, we knew we were going to be subject to competition. Quite simply, we did what we could. But I would have taken these measures anyway, because I had my budget to follow. The fact is that you can do the same things, in terms of boosting efficiency, but under localauthority auspices. All the same, being subject to competition meant that I reviewed my unit's work at an earlier stage and more rapidly than I would have done otherwise.'
\end{abstract}

All the unit managers tried to estimate how large a proportion of savings in their unit they were prepared to attribute to the fact that it faced competition. The result is shown in Figure 4 below.

\begin{tabular}{|c|c|c|}
\hline $\begin{array}{l}\text { Type of } \\
\text { service }\end{array}$ & $\begin{array}{l}\text { Facing } \\
\text { competition }\end{array}$ & $\begin{array}{l}\text { Not yet facing } \\
\text { competition }\end{array}$ \\
\hline $\begin{array}{l}\text { Service flats } \\
\text { Nursing } \\
\text { homes }\end{array}$ & $\begin{array}{lll}0 & 0(\mathrm{H}) & 0(\mathrm{H}) \\
4.2 & 12.9 & 18.7 \\
0 & 0 & 0(\mathrm{H})\end{array}$ & $\begin{array}{lllll}0 & 0.6 & 3.4 & 7.5 & 9.0 \\
9.9 & 16.5 & & \\
0 & 8.8 & & \end{array}$ \\
\hline $\begin{array}{l}\text { Home-help } \\
\text { services } \\
\text { Group } \\
\text { housing }\end{array}$ & $\begin{array}{l}0(\mathrm{H}) \\
1.6\end{array}$ & $0(\mathrm{H})$ \\
\hline $\begin{array}{l}\text { Mean: } \\
\text { H) means that th } \\
\text { eduction measur }\end{array}$ & mpetition programr & $\begin{array}{l}\% \\
\text { stened the cost }\end{array}$ \\
\hline
\end{tabular}

Figure 4. Unit managers' estimates of proportions of savings attributable to competition.

Five of the managers were unwilling to attribute the unit's savings directly to its exposure to competition, but nonetheless stated that it hastened $(\mathrm{H})$ the cost-reducing measures. The 
practice may be regarded as an effect of competition, but is difficult to quantify. In arriving at the mean, these savings were accordingly not attributed to exposure to competition and the proportion is consequently given as zero. This also results in the relatively large proportion of zeros in Figure 4. The mean of the units' estimates of the impact of the competition threat is then between 4 and 5 per cent of the cost reduction.

It may appear noteworthy that the managers in the units that had not yet been subjected to competition tended to attribute larger savings to the competition than those managers whose units had undergone competitive tendering. It would be plausible to assume the opposite situation. However, the explanation may lie in the fact that the units that had not yet faced competition perceived a threat of competition for a longer period. In other words, there was a more protracted threat of competition for these units - hence the larger cost reduction that they attribute to their facing competition.

\section{MANAGERS' OPINIONS OF THE COMPETITION PROGRAMME}

In the course of the interviews, the managers were asked how they assessed the information, training and assistance in achieving local-authority management before and during the competition programme. The managers of units that had been exposed to competitive tendering proved, in general, to be more dissatisfied with these matters than the others. The reason may be that the information and training inputs for the two groups were on a par regardless of the situation of the particular units concerned. The former should reasonably have had a greater need for more specific information and training, since facing competition had to the utmost degree become a reality for these managers. They had also had an opportunity to assess the value of the information and training. For those who had not yet 
become subject to competitive tendering, on the other hand, the information and training received may conceivably not yet have been put to the test.

The material suggests some interesting connections between the above factors and the size of the profit centers' cost reductions. Some of the managers have, for example, interpreted the signals from district management level as if it were predetermined that the activity open to tendering was to be privatised. Comments like the following were sometimes made by the unit managers:

\footnotetext{
'It's purely a matter of economics and politics. Privatisation has been the aim. I believe money is what counts, and nothing else. Quality isn't such a matter of concern.'
}

According to the managers themselves, this also helped to dampen their enthusiasm for writing and submitting tenders for the provision of services. Or, as one manager said:

\footnotetext{
'The local authority didn't have enough time to present its tender — we never had time to plan for the tendering. What's more, all the signs indicated that the service was to be privatised, and we wondered why we had to tender when it was going to become private anyway.'
}

A closer examination of the units' savings also reinforces the impression that these managers' interest had been only lukewarm. Three unit managers expressly interpreted the signals as meaning that privatisation was the aim. At one unit costs rose (3.9 per cent), while the savings were relatively small at the other two units (2.9 and 4.7 per cent).

The material also indicates that the managers who had experienced support or help from the central management in conjunction with their units' exposure to competition tended to have a more positive attitude towards the reform than the others. In this respect, the support may thus 
be of great importance. On the other hand, it is difficult on the basis of the material to discern any connections between support for local-authority management and the units' cost reductions. Nevertheless, many of those who perceived that they received support and help from central level pointed out how important this was, especially before and during the tendering process. Its importance is also suggested by the outcome of the tendering. The three local-authority management units in the study whose tenders were accepted all felt that they received support before and in the course of the tendering.

Another feature distinguishing the profit centers whose tenders were accepted in this study is that the unit in question constituted an entire object of contract. This is not true in most instances of competitive tendering in which local-authority management lost: there, the object of contract instead comprised two or more profit centers. In the latter purchasing processes, the individual unit manager therefore does not influence the outcome of the tender procedure entirely on his own, but depends on the behaviour of his colleagues at the other profit centers included in the object of contract. This may be assumed to have various consequences: either the unit manager's motivation for making the unit more efficient increases, if there is a suspicion that his colleagues are not interested in doing the same; or, alternatively, the unit manager's motivation decreases, if he trusts that his colleagues are making their units efficient enough for the tender.

The usual feature of these purchasing processes is, moreover, that the production manager with an overview of the entire object of contract - is the person ultimately responsible for presenting the tender. This may possibly mean that the individual unit manager does not feel that he is participating in the purchase, nor that he is as responsible for its outcome as when he himself presents the tender. 
Another finding is that no connections are discernible between attitude towards exposure to competition and the size of the units' cost reductions. Nor do there appear to be any connections between the time at the units' disposal for preparing the work and the size of the savings. The amounts saved in the units that have been subjected to competitive tendering did not tend to increase the longer the managers had known when their unit was to face competitive tendering. One explanation may be as follows: to the question of how long the units should have to prepare for a tender procedure, most managers said between six and 12 months. Over half the unit managers, however, had less than six months as their period of preparation. One possible explanation may be that the short preparation period did not allow complete strategies for the units to enhance efficiency in and prepare their work for the tendering. Many respondents also pointed out that the implementation of the reform was much too rapid, or as one manager said:

\footnotetext{
'It's been too much of a rush... No, we never really had time to familiarise ourselves with the issues tendering involved. Perhaps one should be able to have one or two members of staff constantly involved in working on the tender. We were all green to start with, and it was noticeable that the ordering unit was too.'
}

\section{CONCLUDING COMMENTS}

In evaluating a reform of this kind, one should bear in mind that competitive tendering is only one of several models available for local-authority management to govern its activities. Nor is its influence entirely isolated; rather, it works with other, more or less traditional models of governance. This also means that an evaluation that is aimed at isolating effects of an individual phenomenon tends to become complicated. 
The interviews with the unit managers were carried out in an endeavour to enhance understanding of this complexity and, if possible, isolate the effects of the competition threat within the framework of the competition programme, in particular. This also means, for practical reasons, that it was feasible to study only a limited number of cases. The result should therefore be regarded with caution when it comes to generalisations. For the following reasons, however, the outcome suggests that the threat of competition had a substantial impact on the profit centers covered by this study.

Three approaches - based on three simple quantitative models - have been presented for the purpose of isolating effects of the competition threat. Cost-cutting with respect to full-time annual staff appointments has been a consistent variable in all three models. However, this has been juxtaposed with a number of changing variables. Initially, each unit's savings were compared with the saving requirements of the unit concerned. The result showed that saving requirements cannot explain the entire cost reduction in all cases. It is thus possible that other factors as well - including exposure to competition - had a substantial impact on the size of the savings. In a second model, the unit managers were therefore divided into two groups: those who perceived a threat of competition during the period that the competition programme was applied, and those who did not. The result showed that the unit managers who perceived a competition threat pushed through larger savings in their units during the same period than the others. The difference is between five and six percentage points. It may seem plausible to interpret this difference between the groups as an effect of the threat of competition. However, in order to get even closer to a plausible conclusion, a third model was also applied in which the unit managers themselves had to estimate how large a proportion of the unit's savings they were willing to attribute to the fact that it faced competition. The answers varied 
widely between unit managers, but in relation to a mean the result was that between 4 and 5 per cent of the cost reduction is attributable to the fact that the city of Stockholm had introduced competitive tendering.

Accordingly, the strength of the conclusions is the agreement between the three models. The precision of their quantification can always be discussed. But one argument for venturing, in this case, to assess the level of effect is that, regardless of which approach is preferred, the findings point in the same direction. Accordingly, one plausible assumption is that the threat of competition has had an effect in the form of savings. This effect - regarded as a mean - may be estimated at a cost reduction of between 4 and 6 per cent.

It is a matter of speculation whether the studied impact of the threat of competition would be different in other circumstances. This is because one conclusion of the interviews is that central efforts to secure support for the purpose of the reform among the units studied have not been entirely successful. The purpose of introducing competition was, after all, to reduce the costs of maintaining - or enhancing - quality. Nevertheless, it emerged during the interviews that a common view among the managers was that costs were the primary concern of the central management. Quality was relegated to a secondary position. The signals were also, in some cases, interpreted by the unit managers as meaning that the purpose of introducing competition was to privatise care of the elderly, and these managers therefore regarded it as already a foregone conclusion. If the threat of competition is to have any effect, the local-authority management players should reasonably feel that they have a chance of winning the tender procedure; but, as we have seen, this was not always the case. Most of them also had a poor opinion of how the reform had been carried out, their salient criticism being that the city of Stockholm had been far too hasty in implementing competitive 
tendering. One question that arises from these views is whether local-authority management was given time to review its own activities to a desirable extent.

Given that most managers considered that there had been a breakdown in implementation, it is not particularly remarkable that relatively many also thought competition had entailed extensive adverse consequences for care of the elderly. This deep-seated opinion may possibly have been the result of local-authority management losing the tendering procedure on such a large scale (in house lost seven of ten tendering procedurs). Conceivably, it goes against the grain for a loser to assert that the activity taken over by an external care provider has also become better as a result. The result may be that the opposite is claimed. But one adverse effect often pointed out by the unit managers was the anxiety that arose among the staff pending the introduction of competitive tendering, or while they awaited the decision from the ordering unit as to who had won the tender.

Attitudes towards the competition programme thus varied. Among the unit managers, positive and negative attitudes were fairly evenly balanced: in some cases they perceived the competition programme in the city of Stockholm unfavourably, or perhaps as a threat in the true sense of the word, while in others they regarded it favourably, or in other words as a challenge or opportunity.

\section{Epilogue}

In conjunction with the local-authority elections in the autumn of 1994, a new majority emerged in the Stockholm City Council. This majority - led by the Social Democrats subsequently took the decision to halt the competition programme pending an evaluation. The Institute of Local Governments Economics at Stockholm University was commissioned to carry out the evaluation of the competition programme. With the results of this evaluation as a starting point, the new majority gave the go-ahead for continued competitive tendering, with the difference that it was now to be voluntary for the social-service districts. The author of the foregoing article took part in the evaluation, and parts of this article form one of the subsidiary reports in this research project. 


\section{REFERENCES}

Bailey, S. J. \& Davidson C., Did Quality Really Increase Under Local Government CCT, In Montanheiro L et al. "Public and Private Partnerships: Learning for Growth", SHU Press, Sheffield UK, 1997

Baumol, W. J., Panzar, J. C., Willig, R. D., Contestable Markets and the Theory of Industry Structure, Academic Press, USA, 1988

Bishop, M. \& Kay, J., Does privatisation work? - Lessons from the UK, London Business School, 1988

Dodgson, J. S. \& Topham, N., Bus deregulation and Privatisation, Athenaeum Press Limited, England, 1988

Ellwood, S., Cost-based Pricing in the NHS International Market, The Chartered Institute of Management Accountants, University of Aston, Birmingham, 1996

Finance Department, City of Stockholm, Urban Services in Competition, 1992

Finance Department, City of Stockholm, Starting one's own Business, 1993

Hambleton, R., Consumerism, Decentralization and Local Democracy, Public Administration, vol. 66, 1988

Harrison, S., Hunter, D. J., Pollitt, C., The Dynamics of British Health Policy, Unwin Hyman Ltd, London, 1990

Hogberg, O., Cost Effects of Exposure to Competition - a Study of the City of Stockholm's Care of the Elderly, (Institute of Local Government Ecomomics, Stockholm University, 1996)

Jonsson, E., Competition in Health Care - Effects Revealed by Research, SPRI, 1993

Jonsson, E., Competition and Quality - a Study of the City of Stockholm's Care of the Elderly, Institute of Local Government Economics, Stockholm University, 1996

Kerley, R. \& Wynn, D., Competitive Tendering - The Transition to Contracted Service

Provision in Scottish Local Authorities, SLAMC Strathclyde Business School, 1990

Knox, C. \& Young, W., Compulsory Competitive Tendering in Northern Ireland Local

Government - The End of Round One, Local Government Studies, Vol. 21, No. 4, 1995

Sorensen, R. J., The Efficiency of Public Service Provision (SAGE Publications, 1993)

Statistics Sweden, Comparative Figures for the Social Services, Stockholm, 1992

The Local Government Management Board, CCT Information Service, Survey Report No. 11, June 1995

Walsh, K., Contract Management - A New Role for Local Government, Policy Studies Institute, 1989

Walsh, K., Public Services and Market Mechanisms - Competition, Contracting and the New Public Management, Macmillan Press Ltd, 1995 